\title{
Teaching may be hazardous to your marriage
}

\author{
Satoshi Kanazawa ${ }^{\mathrm{a}, *}$, Mary C. Still ${ }^{\mathrm{b}}$ \\ ${ }^{a}$ Department of Sociology, Indiana University of Pennsylvania, Indiana, PA, USA \\ ${ }^{\mathrm{b}}$ Department of Sociology, Cornell University, Ithaca, NY, USA \\ Manuscript received October 21, 1999; revised manuscript January 4, 2000
}

\begin{abstract}
Kenrick et al.'s experiments demonstrate that men who view photographs of physically attractive women or Playboy centerfolds subsequently find their current mates less physically attractive and become less satisfied with their current relationships. What then would be the cumulative effect of being exposed to young, attractive women on a daily basis? Would there be any real consequences to the men's dissatisfaction with their relationships? Secondary school teachers and college professors come in contact with more young women at the peak of their reproductive value than others do. The analysis of a large, representative data set from the United States indicates that, while men in general are less likely to be divorced than women, and secondary school teachers and college professors in general are less likely to be divorced than others, simultaneously being male and being a secondary school teacher or college professor statistically increases the likelihood of being divorced $(p<.05)$. We contend that the contrast effect that Kenrick et al. find in their experiments is cumulative and has real consequences. (C) 2000 Elsevier Science Inc. All rights reserved.
\end{abstract}

Keywords: Mate selection; Contrast effect; Divorce; Remarriage

In laboratory experiments, Kenrick and colleagues found that men who were exposed to photographs of physically attractive women subsequently became less satisfied with their current heterosexual relationships and rated their partners less attractive. Kenrick et al. (1989) in Experiment 2 showed that men who viewed 16 Playboy centerfold slides rated their mates less sexually attractive and reported less love for them than men who viewed 16 abstract art slides. In Kenrick et al. (1994), men who viewed seven photographs of physically attractive women subsequently rated their mates less physically attractive and expressed less commitment to their current relationships than did men who viewed seven photographs of average-looking women.

Kenrick et al.'s experiments immediately suggest two questions. First, if their male subjects became less satisfied with their current relationships and rated their partners as less at-

\footnotetext{
* Corresponding author.

E-mail address: kanazawa@grove.iup.edu (S. Kanazawa).
} 
tractive after viewing a few photographs in an experiment, what would be the cumulative effect of being constantly exposed to young, attractive women on men's relationships? Second, are there any behavioral consequences of their dissatisfaction with their partners as a result of their exposure to physically attractive women?

There is some evidence that men find women in their 20 s, who are at the peak of their fertility, most attractive (Kenrick et al., 1996). However, because women's reproductive value (the number of children they are likely to have in the future) peaks at menarche (Crawford et al., 1989), men's evolved psychological mechanisms might also lead them to find women who are in their teenage years more physically and sexually attractive than older women (despite laws of civilized society concerning the age of consent and the minimum age for marriage). Compared to most adult women, teenage women have the lower waist-to-hip ratios that men prefer (Singh, 1993).

Few occupations and professions afford greater opportunities to come in contact with women in their teenage years than teachers in secondary and postsecondary schools. These teachers experience the cumulative effect of exposure to young, attractive women who are at their peak reproductive value more acutely than people in most other occupations. (They are also exposed to young, attractive men, but we would not expect this to have a comparable effect on women's relationships because women do not value youth and physical attractiveness in mates as much as men do [Buss, 1994: 19-48; Kenrick et al., 1994]). If the findings of Kenrick et al. extend beyond the experimental stimuli (the exposure to a few photographs of attractive women during an experimental session) and if the contrast effect is cumulative, then male teachers in secondary and postsecondary schools should be more dissatisfied with their mates than other people. If there are behavioral consequences to their dissatisfaction, then these male teachers should be more likely to be divorced or separated than others.

We analyzed one of the largest and best social science data sets to test this hypothesis. We used the 20 consecutive waves of the General Social Survey, collected either annually or biennially from 1972 to $1996(n=32,845)$. The respondents for each wave are a representative sample of noninstitutionalized adults in the United States. We regressed the respondent's current marital status (divorced/separated vs. not divorced/separated) on whether they are secondary school or college teachers, their sex, and the interaction between these two variables, as well as their age, race, occupational status, and the survey years.

Table 1 (left column) shows that, in general, men are significantly less likely to be currently divorced or separated than women (due presumably to men's serial polygyny, where divorced men remarry younger women while divorced women are relatively more likely to remain single). In general, secondary school teachers and college professors are less likely to be divorced or separated. However, simultaneously being male and being a secondary school teacher or college professor statistically significantly increases the likelihood of being currently divorced $(p<.05)$.

Table $2 \mathrm{~A}$ presents the mean probabilities of being currently divorced or separated, broken down by sex and occupation (secondary school teachers and college professors vs. others). Table 2A shows that men, in general, have a large "advantage" over women in avoiding the risk of currently being divorced or separated (even though each divorce involves a man and a woman) $(F=173.33, p<.0001)$. Similarly, teachers in general have the same "advantage" over nonteachers $(F=4.46, p<.05)$. However, Table $2 \mathrm{~A}$ demonstrates that being a male 
Table 1

Likelihood of divorce or separation using general social surveys, 1972-1996

\begin{tabular}{lcc}
\hline & Dependent variable & Ever divorced \\
\cline { 2 - 3 } Predictor & Currently divorced & {$[\mathrm{b}(\mathrm{SE})]$} \\
\hline Secondary school teacher or & {$[\mathrm{b}(\mathrm{SE})]$} & $-.4922^{\dagger}$ \\
$\quad$ college professor $(\mathrm{yes}=1)$ & $-.3673^{*}$ & $(.1540)$ \\
Sex $($ male $=1)$ & $(.1799)$ & $-.2129^{\S}$ \\
& $-.4344^{\S}$ & $(.0269)$ \\
Interaction & $(.0333)$ & .3391 \\
& $.5474^{*}$ & $(.2183)$ \\
Age & $(.2559)$ & $-.0096^{\S}$ \\
& $-.0025^{\dagger}$ & $(.0007)$ \\
Occupational status & $(.0009)$ & $.0048^{\S}$ \\
Race $($ black $=1)$ & $-.0032^{*}$ & $(.0010)$ \\
Constant & $(.0012)$ & .0473 \\
& $.6785^{\S}$ & $(.0392)$ \\
$\chi^{2}$ log likelihood $(d f=26)$ & $(.0418)$ & -1.3976 \\
Percent correctly classified & -1.5662 & $(.0573)$ \\
No. of cases & $(.0694)$ & 35096.531 \\
\hline
\end{tabular}

Note: The logistic regression equations also contain survey year as a categorical variable $(d f=20)$.

$* p<.05 ;{ }^{\dagger} p<.01 ;{ }^{\ddagger} p<.001 ;{ }^{\S} p<.0001$.

teacher or professor eliminates these advantages associated with either being male or being a teacher. Among men, teachers are just as likely to be divorced or separated as nonteachers $(F=.00, p>.9)$. Among teachers, men are just as likely to be divorced or separated as women $(F=.01, p>.9)$. The same interaction effect does not hold for kindergarten and grade school teachers (Table 2B). Male kindergarten and grade school teachers retain the "advantages" associated with being a male or being a teacher. There appears to be something about male teachers who come in daily contact with teenage women that increases the likelihood of being currently divorced or separated.

Interestingly, male high school teachers and college professors are not demonstrably more likely to have ever been divorced or separated (Table 1, right column); the positive interaction effect is statistically nonsignificant $(p=.12)$. Table 3 demonstrates the absence of statistically significant interaction effect; male teachers do not lose the "advantage" as much as they do when the dependent variable is whether or not they are currently divorced or separated. [In fact, the probability for male teachers in Table 3A is slightly, albeit nonsignificantly $(p>.79)$, higher than female teachers.] This means that, although male high school teachers and college professors may or may not be more likely to get a divorce than others, they are statistically significantly slower to remarry or more likely not to remarry subsequent to their divorce. We believe that there are two possible interpretations for this finding. First, subsequent to divorce, male teachers and professors may remain unmarried because they prefer to pursue a series of affairs with female students without marrying them. Second, they 
Table 2

Probabilities of being currently divorced or separated by sex and occupation

\begin{tabular}{llll}
\hline (A) High school teachers and college professors & & \\
\hline High school or & Sex & Female & \\
\cline { 2 - 4 } college teacher? & Male & .1088 & .1099 \\
Yes & .1111 & $(340)$ & $(646)$ \\
No & $(306)$ & .1605 & .1389 \\
& .1110 & $(19,477)$ & $(34,638)$ \\
& $(15,161)$ & .1597 & .1383 \\
& .1110 & $(19,817)$ & $(35,284)$ \\
\hline (B) Kindergarten and grade school teachers & $(15,467)$ & & \\
\hline Kindergarten or & Sex & & .0948 \\
grade school teacher? & Male & Female & $(823)$ \\
\hline Yes & .0784 & .0971 & .1394 \\
& $(102)$ & $(721)$ & $(34,461)$ \\
No & .1112 & .1620 & .1383 \\
& $(15,365)$ & $(19,096)$ & $(35,284)$ \\
\end{tabular}

Note: The numbers in parentheses are sample sizes.

may remain unmarried because, due to the cumulative contrast effect, any adult woman they might meet and date after their divorce would still pale in comparison to the young attractive women with whom they come in daily contact.

The GSS data do not allow us to adjudicate between the two alternative hypotheses: however, there are strong indications that male teachers and professors do not engage in a series of affairs with female students. The GSS data show that, compared to other men, male teachers and professors do not have a larger number of sex partners in the last 12 months (1.07 for teachers vs. 1.25 for others, $F=2.10, p>.14$ ). They are not more likely to pursue casual sex exclusively $(9.33 \%$ for teachers vs. $10.50 \%$ for others, $F=.11, p>.74)$. They do not have a larger number of sex partners since their 18th birthday (9.47 vs. $14.26, F=1.52, p>.22$ ). They are not more likely to have an extramarital affair $(21.95 \%$ vs. $23.21 \%, F=.04, p>$ $.85)$. And they are not more likely to approve of premarital sex $(44.16 \%$ vs. $45.46 \%, F=.13$, $p>.72)$, teenage sex $(6.10 \%$ vs. $5.21 \%, F=.13, p>.72)$, or extramarital sex $(5.08 \%$ vs. $3.59 \%, F=1.23, p>.27)$. We therefore believe that it is unlikely that male teachers and professors remain single after their divorce because they pursue a series of affairs with female students.

We instead believe that Kenrick et al.'s contrast effect can account for the fact that male teachers and professors are less likely to remarry subsequent to their divorce. Kenrick et al.'s experiments suggest that men in these occupations become dissatisfied with their wives due to their constant exposure to young, attractive women. So they divorce their wives. Subsequent to their divorce, however, any adult woman they encounter would still not be as attractive as the nubile teenage women whom they observe every day. Our logic therefore would 
Table 3

Probabilities of having ever been divorced or separated by sex and occupation

\begin{tabular}{|c|c|c|c|}
\hline \multicolumn{4}{|c|}{ (A) High school teachers and college professors } \\
\hline \multirow{2}{*}{$\begin{array}{l}\text { High school or } \\
\text { college teacher? }\end{array}$} & \multicolumn{2}{|l|}{ Sex } & \\
\hline & Male & Female & \\
\hline Yes & $\begin{array}{r}.1634 \\
(306)\end{array}$ & $\begin{array}{r}.1559 \\
(340)\end{array}$ & $\begin{array}{r}.1594 \\
(646)\end{array}$ \\
\hline No & $\begin{array}{l}.2082 \\
(15,161) \\
.2073 \\
(15,467)\end{array}$ & $\begin{array}{l}.2419 \\
(19,477) \\
.2405 \\
(19,817)\end{array}$ & $\begin{array}{l}.2271 \\
(34,638) \\
.2259 \\
(35,284)\end{array}$ \\
\hline \multicolumn{4}{|c|}{ (B) Kindergarten and grade school teachers } \\
\hline \multirow{2}{*}{$\begin{array}{l}\text { Kindergarten or } \\
\text { grade school teacher? }\end{array}$} & \multicolumn{2}{|l|}{ Sex } & \\
\hline & Male & Female & \\
\hline Yes & $\begin{array}{r}.1667 \\
(102)\end{array}$ & $\begin{array}{r}.1498 \\
(721)\end{array}$ & $\begin{array}{r}.1519 \\
(823)\end{array}$ \\
\hline No & $\begin{array}{l}.2075 \\
(15,365) \\
.2073 \\
(15,467)\end{array}$ & $\begin{array}{l}.2439 \\
(19,096) \\
.2405 \\
(19,817)\end{array}$ & $\begin{array}{l}.2277 \\
(34,461) \\
.2259 \\
(35,284)\end{array}$ \\
\hline
\end{tabular}

Note: The numbers in parentheses are sample sizes.

predict that divorced male teachers and professors would be less likely to remarry than other divorced men. Our contention is that the daily exposure to young women draws the men's attention to the contrast between the physical body of teenage women that men's evolved psychological mechanisms find attractive and that of adult women, very few of whom can possess or maintain the ideal. This sharp contrast then produces dissatisfaction in the men's mind, and it is this dissatisfaction, rather than the teenage women themselves or affairs with them, that simultaneously leads to an increased risk of divorce or separation and a decreased probability of remarriage.

Our findings from a large sample of respondents in the United States suggest that Kenrick et al.'s experimental findings are indeed cumulative and have some real behavioral consequences. We suggest that male secondary school teachers and college professors have a greater risk of being divorced or separated because they are exposed to young, attractive women on a daily basis. Their more mature wives appear less physically attractive to them, and their commitment to their marriage subsequently wanes. For the same reason, these men appear less likely to remarry subsequent to their divorce compared to other divorced men.

\section{Acknowledgments}

We thank Laura L. Betzig, Paula England, Jeremy Freese, Douglas T. Kenrick, James A. Kitts, Alexandra R. Maryanski, Steven L. Nock, Michael W. Macy, and Alan S. Miller for their comments on the earlier drafts of this paper. 


\section{References}

Buss, D. M. (1994). The Evolution of Desire: Strategies of Human Mating. New York: BasicBooks.

Crawford, C. B., Salter, B. E., \& Jang, K. L. (1989). Human grief: is its intensity related to the reproductive value of the deceased? Ethology and Sociobiology, 10, 297-307.

Kenrick, D. T., Gabrielidis, C., Keefe, R. C., \& Cornelius, J. S. (1996). Adolescents' age preferences for dating partners: support for an evolutionary model of life-history strategies. Child Development, 67, 1499-1511.

Kenrick, D. T., Gutierres, S. E., \& Goldberg, L. L. (1989). Influence of popular erotica on judgments of strangers and mates. Journal of Experimental Social Psychology, 25, 159-167.

Kenrick, D. T., Neuberg, S. L., Zierk, K. L., \& Krones, J. M. (1994). Evolution and social cognition: contrast effects as a function of sex, dominance, and physical attractiveness. Personality and Social Psychology Bulletin, 20, 210-217.

Singh, D. (1993). Adaptive significance of waist-to-hip ratio and female physical attractiveness. Journal of Personality and Social Psychology, 65, 293-307. 